\section{Hepatitis B virus markers on dried blood spots. A new tool for epidemiological research}

ERICA VILLA, ROBERTO CARTOLARI, STEFANO Bellentani, PaOlo Rivasi, ${ }^{*}$ giancarlo CASOlo, FEDERICO MANENTI Institute of Semeiotica Medica and * Blood Transfusion Centre, University of Modena, Italy'

HBsAg testing is widely used as a marker of hepatitis $B$ virus (HBV) infection in epidemiological surveys, but the detection of anti-HBs and anti-HBc antibodies and possibly those of the $\mathrm{HBeAg}$ - anti-HBe system, has now become increasingly important. ${ }^{12}$ Large scale surveys, however, often require facilities not readily available in most of the countries where HBV infection is endemic. Furthermore, all problems are increased when the population under investigation is spread over a large area far from the study centre, especially when repeated controls are required. This needs a simple and reliable method for acquiring and transferring blood samples.

In 1978, Farzadegan et al. ${ }^{3}$ proposed a method for detection of HBsAg on the eluates from dried blood spots. This technique has not been applied to other HBV-related antigen and antibodies. We describe here a modified technique for testing eluates from dried blood spots for $\mathrm{HBsAg}, \mathrm{HBeAg}$, anti-HBe, anti-HBs and anti-HBc.

\section{Material and methods}

Two groups of patients were studied:

Group 1: 12 HBsAg-positive, anti-HBc-positive patients (six chronic asymptomatic carriers, six with chronic active hepatitis). The titre of anti-HBc in all patients was $>1 / 1000$. One of these patients was $\mathrm{HBeAg}$-positive (titre $1 / 100000$ ) and four were antiHBe-positive (titre 1/1000).

Group 2: 12 HBsAg-negative, anti-HBs- and anti-HBc-positive patients (two with chronic persistent hepatitis, five with chronic active hepatitis, five with liver cirrhosis). For both antibodies, titres ranged between $1 / 1$ and $1 / 1000$.

\section{COLLECTION OF SAMPLES}

Capillary blood was collected on filter paper (spots of about $8 \mathrm{~mm}$ diam), air-dried, and stored at room temperature. Similar samples, prepared from eight patients of the second group, were also stored at $+4^{\circ} \mathrm{C}$ and at $-20^{\circ} \mathrm{C}$. Venous blood was also obtained

Accepted for publication 5 November 1980 from the same patients and aliquots of serum kept frozen.

\section{ELUTION AND TESTING}

Blood spots were tested after 1, 7, 15, 30, 60, and 180 days from sampling. Spots were extracted with either 250 or $600 \mu 10.9 \%$ saline for $\mathrm{HBsAg}$, anti-HBs and $\mathrm{HBeAg}$ assays and with either 150 or $600 \mu \mathrm{l}$ for anti-HBc and anti-HBe assays; in the first six patients of each group, spots were eluted for 1,6 , and 12 hours at room temperature; in the remaining patients, spots were eluted overnight.

Eluates and sera were tested by radioimmunoassay (Ausria II, Ausab, Corab, e-anti e RIA kit, Abbott Laboratories). Serial tenfold dilutions of sera were made to estimate the titre of antibodies. Results obtained at different times with kits differing in specific activity were compared for each patient by calculating the ratio between "samples cpm" and "cutoff value" for each experiment.

\section{Results}

For each of the tests, the best separation between positive and negative results was found when spots were extracted for 12 hours. In subsequent experiments, therefore, dried specimens were eluted overnight.

In the HBsAg-positive patients, tests for $\mathrm{HBsAg}$ on dried spots gave positive results after each time interval, without differences due to the elution volumes of 250 and $600 \mu \mathrm{l}$. Anti-HBc testing in the same group of patients consistently yielded positive results, both with 150 and $600 \mu$ l of elution volume. Dried specimens showed a slight loss of activity after 30,60 , and 180 days storage in comparison with serum, although all results were still strongly positive (Fig. 1). In the same group, one patient was $\mathrm{HBeAg}$-positive and four anti-HBe positive, both on serum and eluate, after each time interval. After 15 , 30,60 , and 180 days $\mathrm{HBeAg}$ and anti-HBe results on eluates decreased on average by $20 \%$ in comparison with the corresponding sera.

In the HBsAg-negative, anti-HBs, and anti-HBc positive group anti-HBs and anti-HBc tests gave positive results, with elution volumes of 250 and $150 \mu \mathrm{l}$ respectively, when the antibody titre in serum was $\geqslant 1 / 100$. When the titre was $1 / 10$, the test on eluates gave inconsistent results while eluates were always negative when antibody determination was positive on undiluted serum only. When spots were eluted with $600 \mu \mathrm{l}$, tests were positive only when the antibody titre was at least $1 / 1000$.

Storage at room temperature did not affect results during the whole period of observation, when the antibody titre was $\geqslant 1 / 1000$ but eluates became 


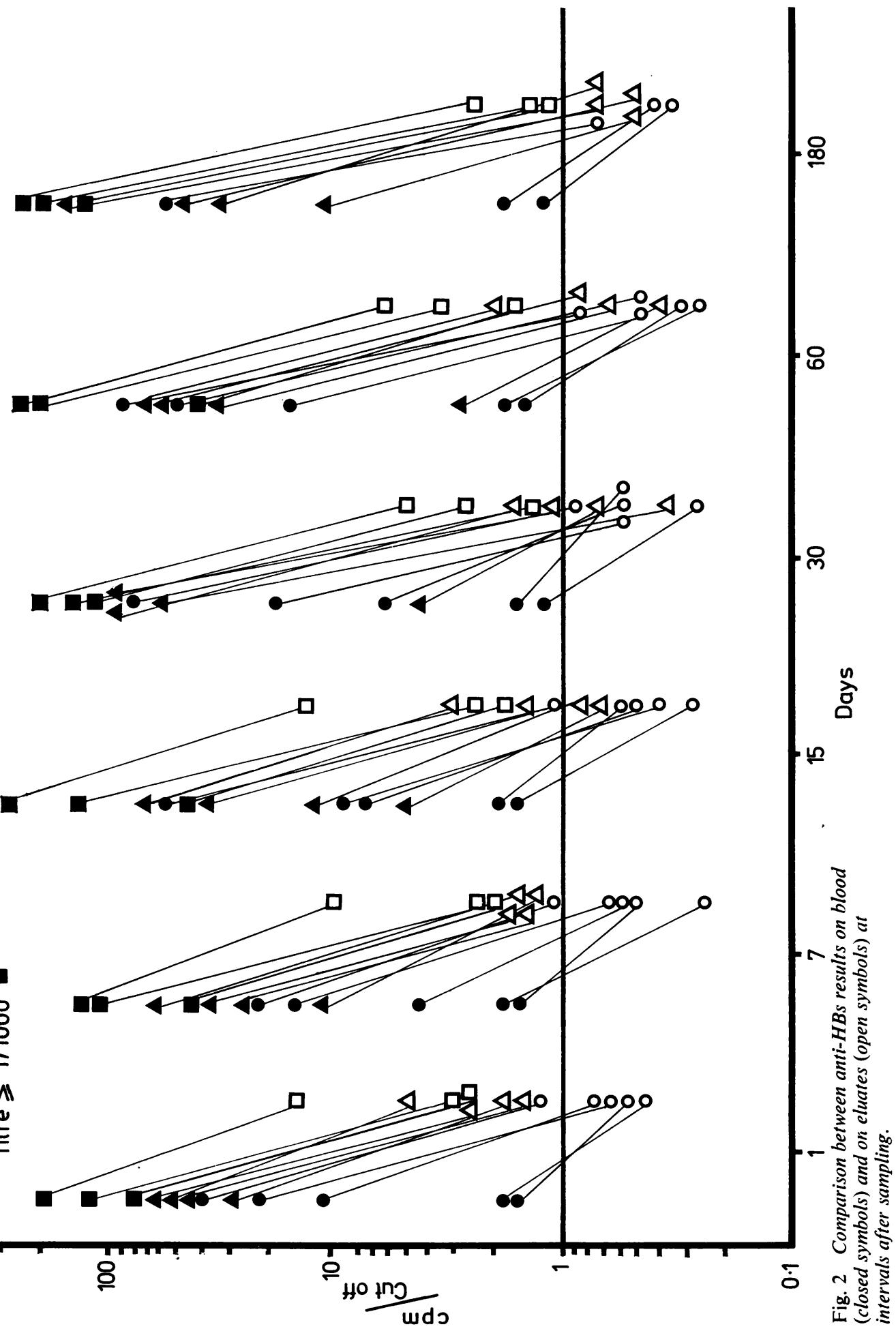


borderline-positive or even negative, after 15 days of storage or more, when the titre in serum was $1 / 100$ (Figs. 1 and 2). Storage at $+4^{\circ} \mathrm{C}$ or at $-20^{\circ} \mathrm{C}$ did not significantly improve results when compared with those stored at room temperature. In patients with the highest antibody titres, the slight loss in activity after 30,60 , and 180 days was, for all three periods of storage, in the range of one dilution in respect to serum levels. In patients with low titres, storage at $+4^{\circ} \mathrm{C}$ or at $-20^{\circ} \mathrm{C}$ did not prevent the test becoming negative.

\section{Discussion}

It seems apparent from our results that HBV markers are stable in a dried condition and that the technique for their determination on eluates from dried specimens is simple, reliable and reproducible.

As far as specificity is concerned, we have never encountered false-positive results although the eluates contained whole blood instead of serum. Sensitivity is not a problem for HBsAg determination. The failure of the method to give positive results when antibody titre in serum was less than $1 / 100$ is probably related to the dilution of the small quantity of blood (about $50 \mu \mathrm{l}$ ) contained in a spot of $8 \mathrm{~mm}$, once this is eluted. Elution with the minimal amountsै necessary to perform the assay, 250 or $150 \mu \Phi$ depending on the test, causes a three- to fivefol dilution of the antibody in comparison with serum? so that antibody activity becomes too weak to be detected. This could probably be obviated b increasing the size of the spot eluted, therefore obtaining a more concentrated solution.

This method seems suitable for epidemiologica出 surveys or large-scale screenings, especially if mailing of specimens is required.

\section{References}

${ }^{1}$ Szmuness W, Harley EJ, Ikram H, Stevens CE. Socio demographic aspects of the epidemiology of hepatitis $B \perp$ In: Vyas GN, Cohen SN, Schmid R, eds. Viral hepatiti. Philadelphia: Franklin Institute Press, 1978:297-320.

${ }^{2}$ Perillo RP, Gelb L, Campbell C, et al. Hepatitis BeAg@ DNA polymerase activity and infection of household contacts with hepatitis B virus. Gastroenterolog. 1979;76? 1319-25.

${ }^{3}$ Farzadegan H, Noori KH, Ala F. Detection of hepatitis surface antigen in blood and blood products dried or filter paper. Lancet 1978 ; ; :362-3.

Requests for reprints to: Dr Erica Villa, Institute of Semeiotica Medica, Policlinico, Via del Pozzo 71, 41100 Modena, Italy.

\section{Letters to the Editor}

\section{Plasma electrolytes in dangerous infectious diseases}

Most of the common laboratory investigations necessary for the diagnosis and management of patients with hazardous infectious diseases can be done in a suitable safety cabinet. ${ }^{1}$ However, plasma sodium and potassium present difficulties as their estimation requires the use of either ion-specific electrodes or a flame photometer.

Potentiometric assay appears to be simpler than flame photometry but we did not consider it appropriate in this case for two reasons: first, the necessary equipment is not generally available and second, flame photometers are rather simpler and more likely to function reliably at very short notice after long periods without attention or maintenance, a situation especially liable to obtain if an instrument is reserved for the relatively infrequent dangerous specimen. On the other hand, flame photometers should not be enclosed in a safety cabinet as they produce much heat and operate on gas and air under pressure.

A solution to this problem is to dilute the plasma or serum sample inside the safety cabinet using formalin as the diluent instead of water. After leaving the bottle of diluted sample in the dunk tank for at least $1 \frac{1}{2} \mathrm{~h}$ (ensuring that the outside is also sterilised) the contents can be analysed in an unenclosed bench flame photometer. We find that very little formaldehyde gets past the flame; even after 15 samples the smell of formaldehyde is minimal.
Although the diluted sample comes $\underset{\text { toto }}{3}$ contact with only plastic and stain Fess steel, distilled water should be run throtgh after use to clear the instrument residual formaldehyde.

Plasma diluted in formalin in this yields a faintly turbid suspension Of $^{\circ}$ precipitated protein. To check that migho organisms trapped within such protein floccules are inactivated, we diluted in formalin $(1 / 100)$, fresh human plasmato which Bacillus globigii spores had b\&en added giving a final concentration * of $10^{8} / \mathrm{ml}$ of plasma. At $10,20,45$, and 90 min after dilution the precipitates from $1 \mathrm{ml}$ volumes of the diluted plasma were washed and one loopful was added to $5 \mathrm{~g}$ l of nutrient broth and another plated nutrient agar. Growth was obtained omly 